\title{
Antibiotic resistance profile of $E$. coli isolates in 17 municipal wastewater utilities across Oregon
}

Marjan Khorshidi-Zadeh ${ }^{\mathrm{a}}$, Sue Yee Yiu ${ }^{\mathrm{a}}$, Jacquelynn N. Nguyen ${ }^{\mathrm{a}}$, Gabriela L. Garza ${ }^{\mathrm{a}}$, Joy WaiteCusic $^{b}$, Tyler S. Radniecki ${ }^{\mathrm{a}}$, Tala Navab-Daneshmand ${ }^{\mathrm{a}, *}$

${ }^{\mathrm{a}} 105 \mathrm{SW} 26^{\text {th }} \mathrm{St}$, 116 Johnson Hall, School of Chemical, Biological, and Environmental Engineering, Oregon State University, Corvallis, OR 97331, United States

b 3051 SW Campus Way, Department of Food Science and Technology, Oregon State University, Corvallis, OR 97331, United States

*Corresponding author: tala.navab@ oregonstate.edu

\begin{abstract}
Wastewater treatment utilities are considered one of the main sources and reservoirs of antimicrobial resistance. The objective of this study was to determine the diversity and prevalence of antibiotic-resistant Escherichia coli in wastewater treatment systems across the state of Oregon. Influent, secondary effluent, final effluent, and biosolids were collected from 17 wastewater treatment utilities across Oregon during the winter and summer seasons of 2019 and 2020 ( $n=246)$. E. coli strains were recovered from samples by culturing on mTEC, followed by confirmation with MacConkey with MUG agar plates. Antibiotic susceptibility of 1143 E. coli isolates against 8 antibiotics were determined, and resistance profiles and indices were analyzed between utilities, seasons, and flows. Antibiotic resistance phenotypes were detected in $31.6 \%$ of the collected $E$. coli isolates. Among those antibiotic-resistant E. coli isolates, multi-drug resistance (i.e., resistance to three or more classes of antibiotics) was harbored by $27.7 \%$ with some strains showing resistance to up to six classes of antibiotics. The most prevalent resistance was to ampicillin $(n=207)$ and the most common combinations of multi-drug resistance included simultaneous resistances to ampicillin, streptomycin, and tetracycline $(n=49)$, followed by ampicillin, streptomycin, and sulfamethoxazole/trimethoprim $(n=46)$. Significant correlations were observed between resistance to sulfamethoxazole/trimethoprim and resistances to ampicillin, ciprofloxacin, and tetracycline $(p<0.001)$. A small percentage $(1.1 \%)$ of the $E$. coli isolates displayed extended-spectrum beta lactamase (ESBL) activity and a single isolate carried resistance to imipenem. Compared to wastewater influent, ciprofloxacin resistance was significantly more prevalent in biosolids $(p<0.05)$ and tetracycline resistance was significantly lower in effluent $(p<0.05)$. Seasonal impact on antibiotic-resistant $E$. coli in wastewater influent was observed through significantly higher multiple antibiotic resistance (MAR) index, ampicillin resistance prevalence, and ciprofloxacin resistance prevalence in summer compared to winter $(p$ $<0.05)$. This state-wide study confirms the widespread distribution of antibiotic-resistant, multidrug resistant, and extended-spectrum beta lactamase-producing E. coli in wastewater systems across different flows and seasonal variations, making them the recipients, reservoirs, and sources of antimicrobial resistance.
\end{abstract}

Keywords: antimicrobial resistance, Escherichia coli, multidrug resistance, seasonal, wastewater 


\section{Introduction}

Infections with antibiotic-resistant bacteria (ARB) are an urgent and emerging human health concern worldwide due to their association with increased hospital stays, morbidity, and mortality. In the U.S., antibiotic-resistant pathogens are responsible for over 35,000 deaths per year and upwards of $\$ 20$ billion in direct healthcare costs (CDC, 2019, 2013). Municipal wastewater treatment utilities are hotspots for ARB and their determinant genes (Berendonk et al., 2015). Clinically relevant ARB as well as multi-drug resistance (MDR; resistance to three or more classes of antibiotics) phenotypes are present in municipal wastewater (Hoelle et al., 2019). Of importance are critical priority pathogens defined by the World Health Organization, including extended-spectrum beta-lactamases (ESBL)-producing and carbapenem-resistant Enterobacteriaceae (WHO, 2017). Globally, treated or untreated wastewater and biosolids are used for irrigation and soil amendment in agriculture, making soil and food crops potential conduits for human exposure to pathogenic ARB (Mays et al., 2021). Further, there are reports of presence and dissemination of ARB and their determinant genes in environmental reservoirs, such as rivers, lakes, and sediments associated with wastewater discharge (Logan et al., 2020; Quintela-Baluja et al., 2019). Understanding the parameters that impact ARB survival and persistence in wastewater treatment processes will support the development of evidence-based strategies to combat their negative public health impact.

Different wastewater treatment processes impact microbiological quality and hence the ARB load of final effluent and biosolids differently. The biological wastewater treatment compartment can provide favorable conditions for horizontal and vertical transfer of resistance genes via mobile genetic elements within the same or different taxonomic levels of bacteria (Berendonk et al., 2015). Studies have reported increases in the prevalence of E. coli resistant to different antibiotics as well as MDR phenotypes after biological treatments, including activated sludge and lagoons (Kumar et al., 2020; Mezrioui and Baleux, 1994; Zhang et al., 2009). It has been suggested that parameters such as solid retention time, temperature, and type of treatment processes impact ARB levels in biological compartments (Mezrioui and Baleux, 1994; Sui et al., 2017). Disinfection of secondary effluent is suggested to generally reduce ARB levels in the final effluent (Sousa et al., 2017). Subsequently, over 99\% of surviving ARB populations in municipal wastewater influent end up in residual biosolids (Burch et al., 2013a). Advanced sludge treatment processes such as lime stabilization, aerobic digestion, and air-drying beds are capable of reducing ARB populations, whereas other processes (e.g., conventional dewatering, gravity thickening, or anaerobic digestion) have shown little impact (Burch et al., 2013b; Munir et al., 2011).

In addition to treatment processes, seasonal variations can impact ARB populations in wastewater influent as well as the final effluent and biosolids. Seasonal changes can be accompanied by considerable temperature variability, precipitation, as well as increased prescription and consumption of antibiotics. Environmental temperature is an important parameter that can impact the overall microbial diversity (Manaia et al., 2018), horizontal gene transfer rates (Miller et al., 2014), and the incidence of antibiotic resistance genes (Sui et al., 2017) in wastewater. Seasonality in antibiotic concentrations has also been reported in the influent received by wastewater treatment utilities (Golovko et al., 2014). Higher rates of antibiotic-resistant $E$. coli in winter (compared to other seasons) have been reported in wastewater influent obtained from two wastewater utilities in France (Mezrioui and Baleux, 
1994). Similarly, higher abundance of ESBL-producing E. coli have been reported in winter as compared to summer in samples collected from 16 wetlands and three rivers in France (Henriot et al., 2019). Higher precipitation has also been suggested to correlate with increased antimicrobial resistance (AMR) and MDR in enterobacteria in a freshwater watershed in Brazil (Lima-Bittencourt et al., 2007). Others did not observe any significant seasonal associations in ARB populations in an urban-combined sewer system in Japan (Honda et al., 2020). Lack of large-scale studies that include more diverse datasets makes it difficult to arrive at more generalized conclusions from these research findings. There remains a critical need for larger scale, more holistic studies to estimate prevalence and dynamics of ARB in wastewater systems to translate these findings into practical and actionable guidance for the wastewater treatment industry.

The aim of our study was to characterize the antibiotic resistance profile of E. coli (as an indicator of enteric bacteria) in wastewater systems across Oregon, and to determine the impacts of seasonal variations and treatment processes on their fate and presence. To achieve these objectives, wastewater influent, secondary effluent, final effluent, and biosolids were collected from 17 wastewater treatment utilities across the state of Oregon in the winter and summer seasons of 2019 and 2020. The AMR phenotypes of 1143 E. coli isolates were determined, and resistance profiles and indices were analyzed between utilities, seasons, and flows (i.e., influent, secondary effluent, final effluent, or biosolids).

\section{Material and methods}

\subsection{Study sites and sample collection}

Wastewater treatment utilities $(n=17)$ across the state of Oregon were recruited by invitation in this study (Table S1). Sampling was done over two seasons (summer and winter) in the time span of two years (2019 and 2020). Summer samples were collected between the months of July and September and winter samples were collected between January and March. The enrolled treatment utilities served different population densities ranging between 2,00080,000 $(n=11)$, and 80,000-700,000 $(n=6)$. The enrolled utilities were located in the coastal region $(n=2)$, Willamette Valley $(n=10)$ or in Eastern Oregon $(n=5)$. The Oregon climate is divided by the Cascade Range into two main regions. The western part of the state (coastal and Willamette Valley) is influenced by the Pacific Ocean, very wet (161.5 $\mathrm{mm}$ precipitation) with moderate temperatures $\left(2.7 / 10.9^{\circ} \mathrm{C}\right.$; low/average $)$ in winter and dry $(26.6 \mathrm{~mm}$ precipitation $)$ with warm temperatures $\left(11.9 / 24.8^{\circ} \mathrm{C}\right.$ ) in summer (US Climate Data, 2021). The eastern part of Oregon (high desert) has snowy $\left(79.4 \mathrm{~mm}\right.$ precipitation), cold $\left(-2.5 / 8.6{ }^{\circ} \mathrm{C}\right)$ winters and very dry (17.3 mm precipitation) and warm $\left(10.4 / 28.9^{\circ} \mathrm{C}\right)$ summers (US Climate Data, 2021). The minimum distance between adjacent participating utilities was $8 \mathrm{~km}$ and maximum distance was $575 \mathrm{~km}$. Domestic sewage was the main inlet flow to these treatment utilities with the majority receiving less than $20 \%$ industrial wastewater (only one utility receives over $80 \%$ industrial flow). Of the 17 utilities, 12 receive hospital sewage and 10 receive septic sludge. Finally, only three of the wastewater treatment utilities were combined sewer systems that also receive stormwater. Within the study sites, the average daily flow rates during winter (wet) and summer (dry) seasons ranged from 0.8 to 340.7 and 0.8 to 196.8 million L/day, respectively. Treatment processes in the enrolled utilities included some form of primary treatment followed by secondary treatment. The utilities were categorized into two groups according to the secondary 
treatment process (Table $\mathrm{S} 1)$ : the majority of utilities $(n=12)$ used conventional treatment processes (i.e., lagoon, activated sludge, oxidation ditch), and the rest used an advanced treatment (i.e., biological nutrient removal, membrane bioreactor) $(n=5)$. For disinfection, utilities used either chlorine $(n=14)$ or ultraviolet (UV) treatment $(n=4)$. Treated wastewater effluent is discharged to rivers or the Pacific Ocean $(n=13)$, to wetlands and ponds $(n=3)$, or is used for agricultural irrigation $(n=3)$. Biosolids treatment processes included anaerobic digestion $(n=12)$ as the most common method followed by aerobic treatment $(n=2)$, alkaline treatment $(n=2)$, and mechanical dewatering $(n=1)$. Treated biosolids, if available $(n=15)$, are land applied $(n=11)$, disposed of in landfills $(n=2)$, or both $(n=2)$. Only two of the study sites produce Class A biosolids as defined by the U.S. Environmental Protection Agency (US EPA, 1999). From each wastewater treatment utility, samples of influent (1 L), secondary effluent (after biological treatment and before disinfection; $1 \mathrm{~L}$ ), final effluent (1 L), and treated biosolids $(500 \mathrm{~g})$ were collected. During the four sampling campaigns (winter 2019, summer 2019, winter 2020, and summer 2020) a total of 246 samples were collected from the 17 participating wastewater treatment utilities. Biosolids were not collected from utility F in summer 2019. Additionally, no samples were collected from utility A in winter 2019 nor from utilities A, C, F, and $\mathrm{K}$ in summer 2020 (due to challenges associated with the COVID-19 pandemic). Samples were stored on ice and transported or shipped to the laboratory at Oregon State University where they were processed within 24 hours of collection.

\subsection{Physical and chemical parameters}

Total solids, total and volatile suspended solids, $\mathrm{pH}$, and conductivity were measured using standard methods (APHA, 2012; US EPA, 1983). Total solids of biosolids samples were determined by differential mass (starting mass: $2 \pm 0.4 \mathrm{~g}$ ) after drying overnight at $104 \pm 1{ }^{\circ} \mathrm{C}$. Total suspended solids were determined for wastewater influent (up to $75 \mathrm{~mL}$ ) and final effluent (150 mL) by filtering through $1.2 \mu \mathrm{m}$ glass microfiber filter (Whatman, Kent, UK) followed by drying at $104 \pm 1{ }^{\circ} \mathrm{C}$ for 2 hours. Volatile suspended solids were determined by differential mass of the filter before and after ignition at $550^{\circ} \mathrm{C}$. Influent and final effluent $\mathrm{pH}$ and conductivity were measured (sympHony, Radnor, PA) after mixing on stir plate for $10 \mathrm{~min}$. For biosolids, $2 \pm$ $0.4 \mathrm{~g}$ of solids were mixed with $18 \mathrm{~mL}$ of deionized water for 20 minutes prior to $\mathrm{pH}$ and conductivity measurements. Ammonia levels were measured in wastewater influent and final effluent using Hach method 10031 for high range samples (Hach, Loveland, CO).

\section{3. $E$. coli isolation}

To isolate E. coli colonies from secondary effluent and final effluent, up to $400 \mathrm{~mL}$ of well-mixed samples were vacuum filtered on a $0.45 \mu \mathrm{m}$ mixed-cellulose ester membrane (Whatman, Kent, UK). Filters were placed on m-TEC ChromoSelect agar (Sigma Aldrich, St. Louis, MO) plates. Wastewater influent and biosolids were streaked directly onto m-TEC agar plates. Plates were incubated at $44.5 \square$ for 22-24 hours. Colonies displaying a purple/magenta color were considered to be presumptive E. coli. Typical colonies (1-11 per sample) were transferred to LB broth and incubated at $37 \square$ for 16-18 hrs. Isolates were streaked onto MacConkey agar with MUG (Hardy Diagnostics, Santa Maria, CA). After incubation at $37{ }^{\circ} \mathrm{C}$ for 18-24 hours, isolates were considered to be confirmed as E. coli if they were pink in color and exhibited fluorescence under blue-green long-wave UV light (366 nm). Confirmed isolates were cultured in LB broth at $37^{\circ} \mathrm{C}$ for $16-18$ hours, supplemented with $20 \%$ glycerol, and stored at $-20{ }^{\circ} \mathrm{C}$ for later analysis. The number of isolates collected from each flow (i.e., influent, 
secondary effluent, final effluent, and biosolids) from each facility during each sampling season are shown in Figure S1.

\subsection{Antibiotic susceptibility testing}

Antibiotic susceptibility phenotypes of E. coli isolates $(n=1143)$ were determined using the standard disk diffusion technique following the Clinical and Laboratory Standards Institute guidelines (CLSI, 2020). The antibiotics used in this study were ampicillin (10 $\mu \mathrm{g})$, cefotaxime $(30 \mu \mathrm{g})$, ceftazidime $(30 \mu \mathrm{g})$, ciprofloxacin $(5 \mu \mathrm{g})$, imipenem $(10 \mu \mathrm{g})$, streptomycin $(10 \mu \mathrm{g})$, sulfamethoxazole/trimethoprim (SXT) $(1.25 / 23.75 \mu \mathrm{g})$, and tetracycline $(30 \mu \mathrm{g})$ (Hardy Diagnostics, Santa Maria, CA; BD Diagnostics, Sparks, MD). The zones of inhibition were measured, and isolates were classified as resistant or susceptible according to CLSI ranges; isolates classified as intermediate are also reported as 'resistant' in this study. Quality control checks were performed between every 25 tests using E. coli strain ATCC 25922. An isolate was considered multi-drug resistant (MDR) if resistant to three or more of the antibiotics tested. Prevalence of AMR and MDR phenotypes is defined by the presence of resistance within any of the isolates collected from a single sample. The multi-antibiotic resistance (MAR) index of each sample was calculated as $a /(b \times c)$, where $a$ is the total number of resistances observed within isolates collected from the sample, $b$ is the number of the tested antibiotics $(n=8)$ and, $c$ is the number of $E$. coli isolates collected from that sample (Krumperman, 1983).

\subsection{Extended-spectrum beta-lactamase (ESBL) testing}

$E$. coli isolates were tested for the production of ESBL enzyme using the combination disk test (CLSI, 2020). Zones of inhibition to disks containing cefotaxime (30 $\mu \mathrm{g})$, ceftazidime $(30 \mu \mathrm{g})$, cefotaxime/clavulanic acid $(30 / 10 \mu \mathrm{g})$, and ceftazidime/clavulanic acid $(30 / 10 \mu \mathrm{g}) \mathrm{were}$ measured (BD Diagnostics, Sparks, MD). A difference in zone of inhibition of $\geq 5 \mathrm{~mm}$ diameter between antibiotic and antibiotic-acid disk combinations signified the production of ESBL enzyme. An internal quality control and E. coli ATCC 25922 strain were used as ESBL-positive and ESBL-negative controls, respectively.

\subsection{Statistical analysis}

All statistical analysis was performed using R (version 4.0.3, The R Foundation, Vienna, Austria). A Kruskal-Wallis rank test was used to compare antibiotic-resistant E. coli in wastewater influent in different wastewater treatment utilities. Pearson's chi-square test and generalized estimating equation models in $\mathrm{R}$ "geepack" package were used to investigate dynamics of resistance prevalence of different phenotypes in influent compared to secondary effluent, final effluent, and biosolids while accounting for temporal autocorrelation and cluster effects. Prevalence of different AMR phenotypes were set as the response variables and wastewater flow (i.e., influent, secondary effluent, final effluent, or biosolids) as the predictive variable. To test for the impact of seasonal variability on AMR E. coli in wastewater influent, generalized linear models (GLM) were developed using cluster-robust variance estimators with $\mathrm{R}$ “clubSandwich" package. In these tests, prevalence of different AMR phenotypes was set as the response variable and the predictor variables were seasons (winter or summer) and the interaction of seasons and region (Eastern Oregon or coastal/Willamette Valley). A similar procedure was taken by developing a linear model for determining the impact of seasonal variations on MAR index in wastewater influent. Pearson's chi-squared tests were performed on pairwise phenotypes to analyze the co-occurrence of different resistances in E. coli isolates. 
Statistical significance was defined using an $\alpha=0.05$. The Bonferroni correction was used to correct the p-values for multiple tests.

\section{Results and discussion}

\subsection{Physical and chemical characteristics of wastewater treatment utilities}

The average wastewater physical-chemical characteristics for each wastewater treatment utility are reported in Table S2. Near-neutral $\mathrm{pH}$ was detected in wastewater influent, secondary effluent, and final effluent. The average $\mathrm{pH}$ of biosolids was $8.5 \pm 0.4$ (average \pm standard error) and $8.7 \pm 0.4$ in winter and summer, respectively. When data from alkaline treated biosolids were excluded, the average $\mathrm{pH}$ was $8.0 \pm 0.3$ in winter and $8.0 \pm 0.2$ in summer. Total suspended solids, volatile suspended solids, ammonia, and conductivity in the influent were observed to be on average higher in summer compared to winter. These levels (solids, ammonia, and conductivity) generally decreased from wastewater influent to final effluent.

\subsection{Dynamics of antibiotic-resistant $E$. coli in different flows in Oregon wastewater utilities}

A total of 1143 E. coli isolates were collected from wastewater influent, secondary effluent, final effluent, and treated biosolids in winter and summer of 2019 and 2020 from the 17 participating wastewater treatment utilities across Oregon (Figure S1). Overall, 31.6\% $(n=361)$ of all $E$. coli isolates harbored resistance to at least one of the eight tested antibiotics. Of these, $57.3 \%(n=207)$ were resistant to ampicillin, followed by $43.8 \%(n=158), 42.9 \%(n=155)$, $20.5 \%(n=74), 20.2 \%(n=73), 5.5 \%(n=20)$, and $4.2 \%(n=15)$ to tetracycline, streptomycin, ciprofloxacin, SXT, cefotaxime, and ceftazidime, respectively (Figure 1a). Only one isolate harbored resistance to imipenem which was collected from a secondary effluent sample (Figure $1 b)$. Among the antibiotic-resistant $E$. coli isolates, $27.2 \%(n=100)$ carried MDR phenotypes. In wastewater influent, $28.0 \%$ of isolated $E$. coli harbored resistance to at least one of the eight tested antibiotics, ranging from $31.3 \%$ in winter to $25.3 \%$ in summer, with similar rates between geographical regions (27.5\% in Eastern Oregon vs. $28.2 \%$ in coastal and valley region; Figure 1b-e). Resistance to ampicillin (14.6\%), tetracycline (14.6\%), and streptomycin $(12.4 \%)$ were the most prevalent AMR phenotypes in wastewater influent (Figure 1a). Of the 102 antibioticresistant $E$. coli isolates from wastewater influent, 20.6\% harbored MDR phenotype with similar rates between seasons or geographical regions (Figure 1b-e). In secondary effluent, we report that $31.4 \%$ of $E$. coli isolates harbored resistance to at least one antibiotic, of which $29.0 \%$ carried MDR phenotypes (Figure 1a). The AMR rates in secondary effluent were similar between winter and summer or between Eastern Oregon and the coastal/valley regions. Our data on $E$. coli isolates from final effluent shows $31.7 \%$ resistance to at least one of the eight tested antibiotics (Figure 1a). AMR rates in final effluent ranged from $42.1 \%$ in winter to $20.0 \%$ in summer with $26.7 \%$ in Eastern Oregon to $33.1 \%$ in the coastal and valley region (Figure 1b-e). Of the $65 \mathrm{E}$. coli isolates that harbored resistance to at least one of the tested antibiotics in final effluent, $27.7 \%(n=18)$ were MDR. Similar to the influent flow, our findings highlight ampicillin $(21.3 \%)$, streptomycin $(14.4 \%)$, and tetracycline $(11.9 \%)$ as the antibiotics least effective against $E$. coli isolated from final effluent. Finally, of the 259 E. coli colonies isolated from biosolids $36.2 \%$ were resistant to at least one of the eight tested antibiotics. We observed the highest rates of AMR in biosolids. Biosolids isolates of $E$. coli were resistant to ampicillin $(19.7 \%)$, tetracycline (15.4\%), ciprofloxacin (15.4\%), streptomycin (13.9\%). Moreover, 34.0\% of antibiotic-resistant $E$. coli colonies collected from biosolids showed MDR phenotypes. 
medRxiv preprint doi: https://doi.org/10.1101/2021.11.15.21266366; this version posted November 16, 2021. The copyright holder for this preprint (which was not certified by peer review) is the author/funder, who has granted medRxiv a license to display the preprint in perpetuity.

It is made available under a CC-BY-ND 4.0 International license .
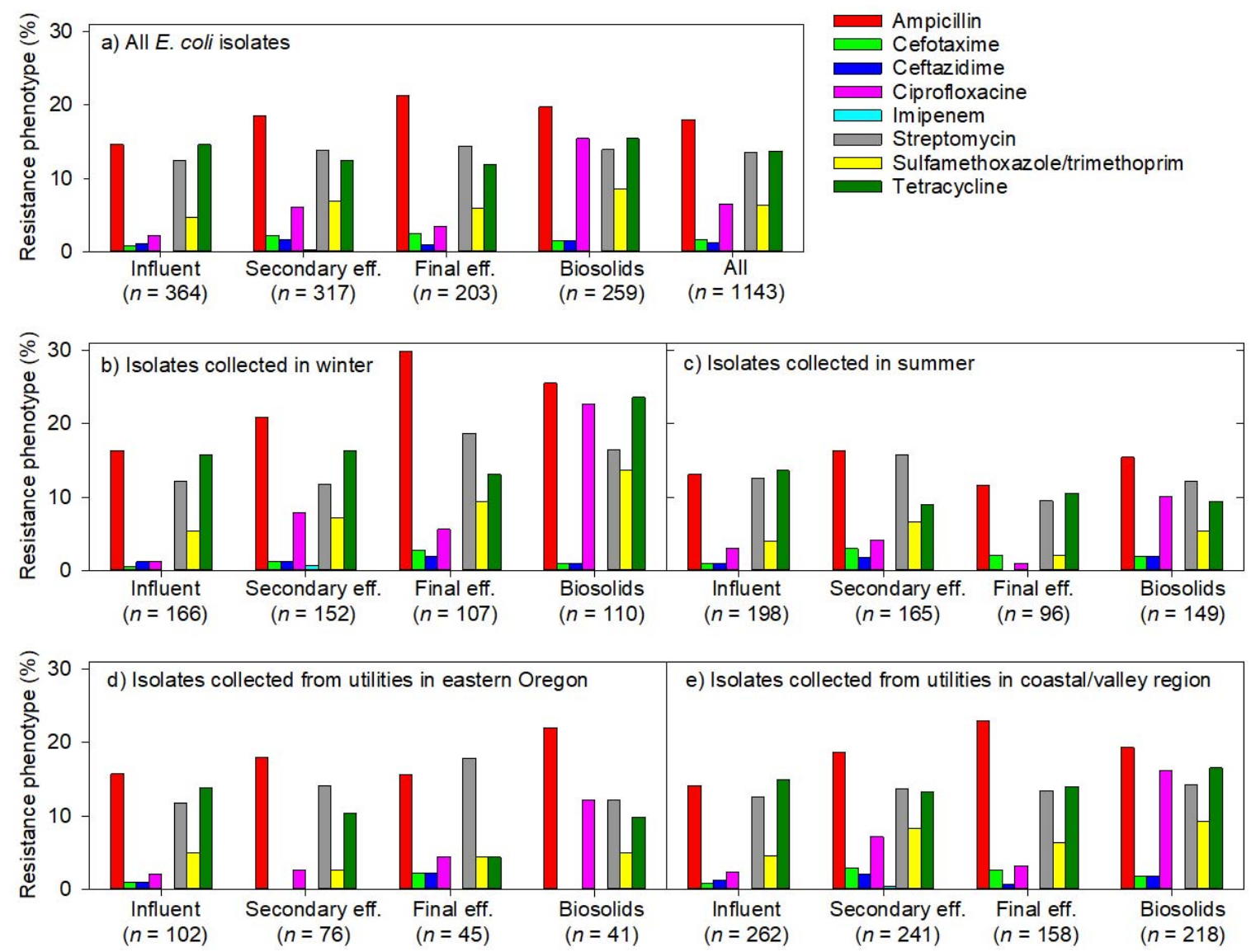

Figure 1. Percentage of antibiotic resistance phenotypes of $E$. coli isolates $(n=1143)$ collected from influent, secondary effluent, final effluent, and treated biosolids from wastewater treatment utilities across Oregon ( $n=5$ in Eastern Oregon, $n=12$ in Willamette Valley/coastal regions) in winter and summer over two years (2019 and 2020). Resistance phenotype is displayed as percentage of isolates with intermediate to resistant classification to eight different antibiotic(s) based

on

CLSI guidelines

(2020). 

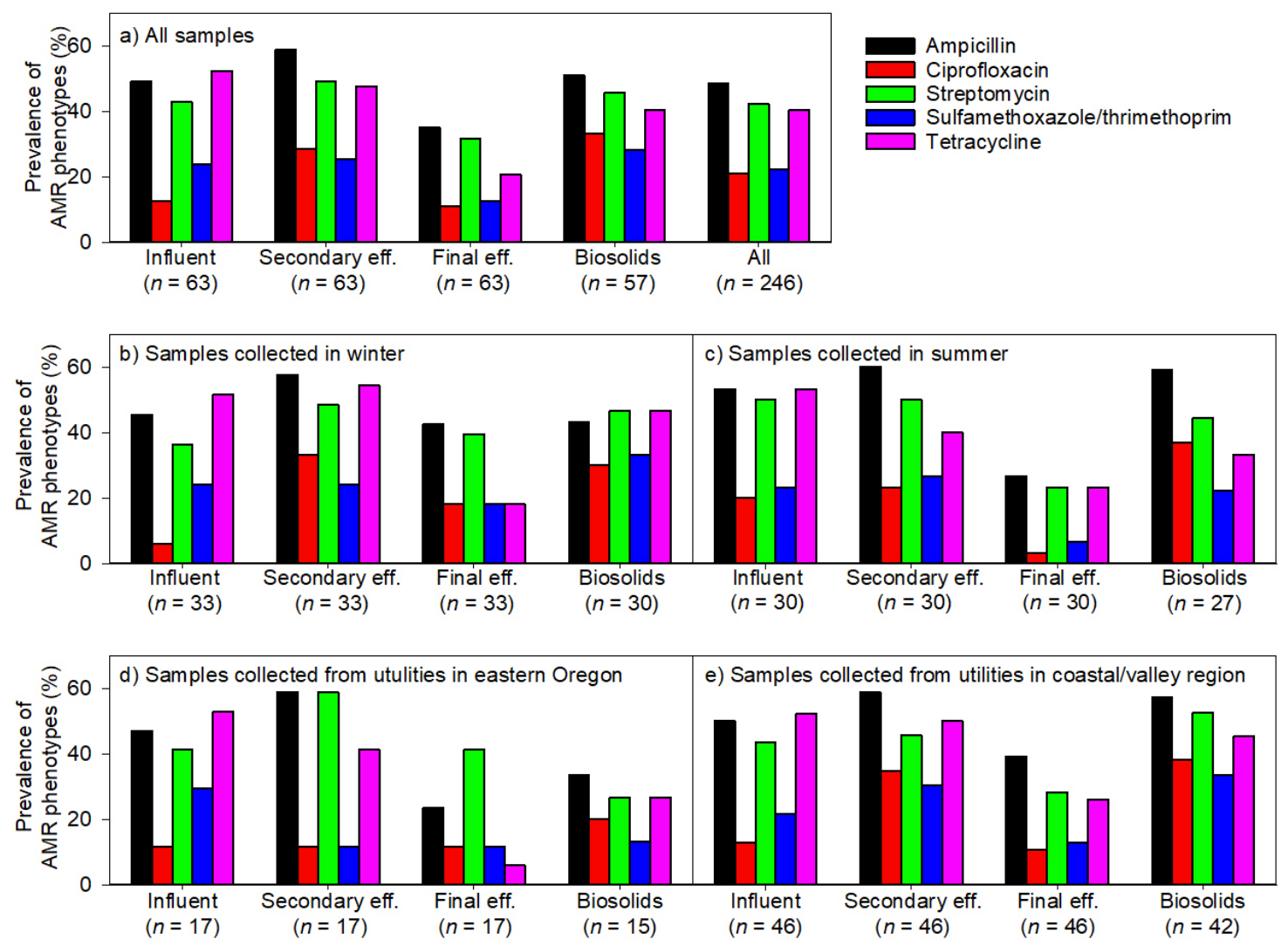

Figure 2. Prevalence of antibiotic-resistant E. coli in different flows (i.e., influent, secondary effluent, final effluent, and biosolids) from wastewater treatment utilities across Oregon ( $n=5$ in Eastern Oregon, $n=12$ in Willamette Valley/coastal regions) in winter and summer over two years (2019 and 2020). Prevalence of resistance phenotype is displayed as presence/absence based on resistance within any of the isolates collected from a single sample. AMR: antimicrobial resistance (i.e., resistance to $\geq 1$ of the tested antibiotics).

In collected samples $(n=246)$, AMR phenotypes were prevalent in $81.0 \%$ of influent samples $(n=63), 77.8 \%$ of secondary effluent $(n=63), 52.4 \%$ of final effluent $(n=63)$, and $71.9 \%$ of biosolids ( $n=57$ ) (Figure $2 \mathrm{a}$ ). Considering dynamics of the AMR phenotypes' pressure between wastewater flows (i.e., influent compared to secondary effluent, final effluent, and biosolids), higher prevalence of ciprofloxacin-resistant $E$. coli was observed in secondary effluent $(28.6 \% ; p=0.02 ; p>0.05$ with Bonferroni correction; Table S3a-b) and biosolids (33.3\%, $p<0.001 ; p<0.01$ with Bonferroni correction; Table S3a-b) compared to influent $(12.7 \%)$ (Figure 2a, Table S3a and b). E. coli isolated from final effluent harbored significantly lower $(20.6 \%, p=0.004 ; p<0.05$ with Bonferroni correction; Table S3a-b) tetracycline resistance phenotype as compared to influent flow (52.4\%). When excluding missing data (i.e., only including utilities B, D-J, M-Q with samples from summer 2019, winter 2020, and summer $2020 ; n=153$ ) results demonstrated higher prevalence of ciprofloxacin-resistant $E$. coli in biosolids compared to influent ( $p=0.01 ; p>0.05$ with Bonferroni correction; Table S3a and $b$ ). Moreover, among all samples $(n=246)$, MAR index ranged between 0 to 0.38 with an average of $0.08 \pm 0.01$ (Figure 3). The average MAR index was $0.06 \pm 0.01$ in influent and $0.08 \pm 0.01$ in secondary effluent and final effluent. MAR index of 0.2 has been suggested as a threshold indicator for an environment with high-risk AMR exposure (Harnisz et al., 2011). In our study, 
of the 246 sampling incidences, 21 samples from 11 wastewater treatment utilities exhibited a MAR index above 0.2: two influent, six secondary effluent, seven final effluent, and six biosolids (Figure 3).

\subsection{Impact of seasonal variations on antibiotic-resistant $E$. coli in wastewater influent}

We studied the impact of seasonal variations (winter vs summer) while controlling for regional effects (Eastern Oregon vs coastal/valley) on AMR E. coli in wastewater influent ( $n=$ 63). Our data shows significantly higher prevalence of ciprofloxacin-resistant $E$. coli in influent in summer samples as compared to winter $(p<0.001 ; p<0.05$ with Bonferroni correction; Table 1 ; Figure $2 \mathrm{~b}-\mathrm{c})$. In addition, in winter season, the prevalence of ciprofloxacin resistance in influent collected from coastal/valley was higher $(p<0.001 ; p<0.05$ with Bonferroni correction; Table 1; Figure 2b-e) than Eastern Oregon samples (Table 1). To further investigate the impact of seasonal variations on antibiotic-resistant $E$. coli in influent, we focused on summer 2019 and winter 2020 samples, excluding seasons with missing samples $(n=34$; Figure S1). When only comparing influent samples between summer 2019 and winter 2020, MAR index, ampicillin resistance prevalence, and ciprofloxacin resistance prevalence were significantly higher in summer compared to winter $(p=0.02,<0.001$, and $<0.001$, respectively, with $p<0.05$ with Bonferroni correction for all three tests; Table 1). When controlled for regional variations in winter influent samples, higher MAR index was observed in coastal/valley compared to Eastern Oregon over both seasons $(p=0.02$ in winter and $p=0.03$ in summer; $p>$ 0.05 for both seasons with Bonferroni correction; Table 1; Figure 3). Controlled for regional variations, findings also demonstrate significantly higher ampicillin resistance prevalence, ciprofloxacin resistance prevalence, and SXT resistance prevalence in coastal/valley compared to Eastern Oregon $(p<0.001$ and $p<0.05$ with Bonferroni correction for the other three tests; Table 1; Figure 2b-e).

Different observations on the seasonal variability of ciprofloxacin have been previously reported. For example, ciprofloxacin resistance was not impacted by seasonal changes in the blood stream isolates of E. coli (Ramsey et al., 2019), whereas higher rates were reported in winter in urinary tract infection studies (Soucy et al., 2020). Accordingly, there are higher prescriptions of ciprofloxacin antibiotic over summer associated with higher rates of urinary tract infections as well as skin and soft tissue infections (Durkin et al., 2018). Ciprofloxacin resistance has been increasing over the past 20 years and has been associated with higher usage of this antibiotic in inpatient care units and outpatient treatments in the U.S. (Sanchez et al., 2012). 
Table 1. Seasonal variability of AMR E. coli in wastewater influent. Linear model's estimates and standard errors reported for MAR index in wastewater influent. Generalized linear models and cluster-robust variance estimates and standard errors reported for prevalence of different antibiotic resistance phenotypes. Seasons (winter $(\mathrm{W})$ and summer $(\mathrm{S})$ ) and interaction between seasons and region (Eastern Oregon (E) and coastal/valley (CV)) were set as predictor variables. Analyses are shown for all samples as well as samples collected in summer 2019 and winter 2020, excluding seasons with missing samples. SXT: sulfamethoxazole/trimethoprim. * $p<0.05, * * p<0.01, * * * p<0.001$. Significant correlations with Bonferroni correction are highlighted in bold.

\begin{tabular}{|c|c|c|c|c|c|c|c|}
\hline \multirow[t]{2}{*}{ Resistance coefficient } & \multirow[b]{2}{*}{ Dependent variable } & \multicolumn{3}{|c|}{ All samples } & \multicolumn{3}{|c|}{$\begin{array}{c}\text { Summer } 2019 \text { \& winter } 2020 \\
\text { samples }\end{array}$} \\
\hline & & Estimate & Standard error & $\mathrm{p}$-value & Estimate & Standard error & $\mathrm{p}$-value \\
\hline \multirow[t]{3}{*}{ MAR index } & Season $(\mathrm{W})$ & -0.04 & 0.03 & 0.13 & -0.07 & 0.03 & $0.02 *$ \\
\hline & Season (W):region $(\mathrm{CV})$ & 0.03 & 0.02 & 0.19 & 0.06 & 0.02 & $0.02 *$ \\
\hline & Season (S):region (CV) & -0.03 & 0.02 & 0.18 & -0.05 & 0.02 & $0.03 *$ \\
\hline \multirow[t]{3}{*}{ Ampicillin prevalence } & Season $(\mathrm{W})$ & -2.35 & 1.90 & 0.29 & -19.95 & 1.25 & $<0.001 * * *$ \\
\hline & Region (CV) & -1.47 & 1.41 & 0.34 & -2.48 & 1.43 & 0.13 \\
\hline & Season $(\mathrm{W})$ :region $(\mathrm{CV})$ & 2.98 & 1.99 & 0.19 & 21.74 & 1.57 & $<0.001 * * *$ \\
\hline \multirow[t]{3}{*}{ Ciprofloxacin prevalence } & Season $(\mathrm{W})$ & -17.47 & 1.30 & $<0.001 * * *$ & -17.18 & 1.25 & $<0.001 * * *$ \\
\hline & Region (CV) & -0.41 & 1.41 & 0.78 & 0.29 & 1.43 & 0.85 \\
\hline & Season (W):region (CV) & 16.62 & 1.66 & $<0.001 * * *$ & 15.88 & 1.87 & $<0.001 * * *$ \\
\hline \multirow[t]{3}{*}{ Streptomycin prevalence } & Season $(\mathrm{W})$ & -1.76 & 1.35 & 0.27 & -2.77 & 2.50 & 0.33 \\
\hline & Region (CV) & -0.88 & 1.02 & 0.42 & -2.08 & 1.40 & 0.19 \\
\hline & Season $(\mathrm{W})$ :region $(\mathrm{CV})$ & 1.87 & 1.40 & 0.23 & 3.47 & 2.70 & 0.24 \\
\hline \multirow[t]{3}{*}{ SXT prevalence } & Season $(\mathrm{W})$ & -0.74 & 0.42 & 0.16 & -0.98 & 1.02 & 0.39 \\
\hline & Region (CV) & -0.99 & 1.20 & 0.43 & -19.16 & 1.02 & $<0.001 * * *$ \\
\hline & Season (W):region (CV) & 1.21 & 0.77 & 0.16 & 19.85 & 1.20 & $<0.001 * * *$ \\
\hline \multirow[t]{3}{*}{ Tetracycline prevalence } & Season $(\mathrm{W})$ & -1.79 & 1.06 & 0.17 & -1.79 & 2.04 & 0.43 \\
\hline & Region (CV) & -1.28 & 0.86 & 0.19 & 0.74 & 1.19 & 0.55 \\
\hline & Season $(\mathrm{W})$ :region $(\mathrm{CV})$ & 2.42 & 1.29 & 0.11 & 3.22 & 2.30 & 0.20 \\
\hline
\end{tabular}




\subsection{Impact of treatment process on antibiotic-resistant E. coli}

Calculated MAR index is shown for each flow and utility based on season and collection year (Figure 3). In both seasons, the averages for MAR index were slightly higher in the secondary effluent compared to the influent. We observed a higher mean MAR index in secondary effluent flow compared to the influent in eight of the 13 wastewater treatment utilities that used conventional biological treatment processes (i.e., activated sludge or lagoon). An increase in average MAR index from influent to secondary effluent was also observed in two of the four utilities with advanced treatment systems (i.e., membrane bioreactor and elevated nutrient removal). Our findings demonstrate increases of MAR index from influent to secondary effluent in 11 of the 17 wastewater treatment utilities, including those with advanced treatment systems, delineating the potential proliferation of AMR in biological treatment systems. This is contrary to several reports showing effective AMR removal during advanced biological treatments, including membrane bioreactors and advanced nutrient removal processes (Korzeniewska and Harnisz, 2018; Munir et al., 2011). Even though increases in antibioticresistant bacteria and determinant genes after biological treatment has been previously reported (Honda et al., 2020; Kumar et al., 2020; Mezrioui and Baleux, 1994; Zhang et al., 2009), the potential link between the role of the treatment process and proliferation of AMR remains unclear.

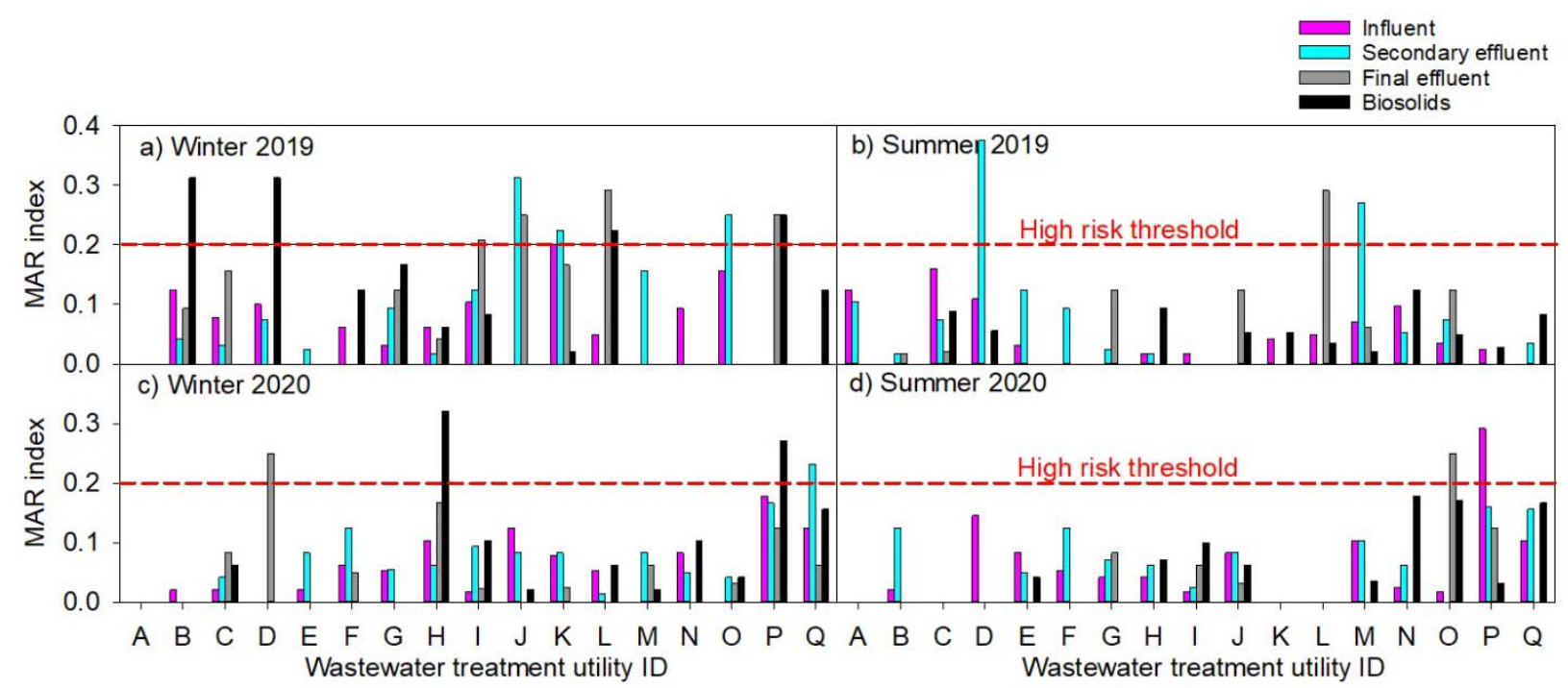

Figure 3. Multi-antibiotic resistance (MAR) index of E. coli isolated from wastewater influent, secondary effluent, final effluent and biosolids. Samples were collected from 17 wastewater treatment utilities across Oregon during winter and summer over two years (2019 and 2020).

In all utilities, chlorination and/or UV were used for disinfection of the secondary effluent, after which $32.0 \%$ of the collected $E$. coli colonies were resistant to at least one of the eight tested antibiotics (27.2\% of which were MDR) in the final effluent. Amongst the wastewater treatment utilities applying UV disinfection, the average MAR index did not change $(\sim 0.12)$ from secondary effluent to final effluent. Comparatively, in wastewater treatment utilities utilizing chlorine, MAR index decreased slightly from secondary effluent $(0.10)$ to final effluent (0.08). 
medRxiv preprint doi: https://doi.org/10.1101/2021.11.15.21266366; this version posted November 16, 2021. The copyright holder for this preprint (which was not certified by peer review) is the author/funder, who has granted medRxiv a license to display the preprint in perpetuity.

It is made available under a CC-BY-ND 4.0 International license .

In treated biosolids (collected after anaerobic digestion, aerobic treatment, alkaline treatment, or mechanical treatment), 36.9\% of the isolates harbored AMR with highest rates of MDR in comparison to other flows' phenotypes (34.0\% of AMR population). The average MAR index in biosolids was $0.13 \pm 0.02$ in winter and $0.07 \pm 0.01$ in summer.
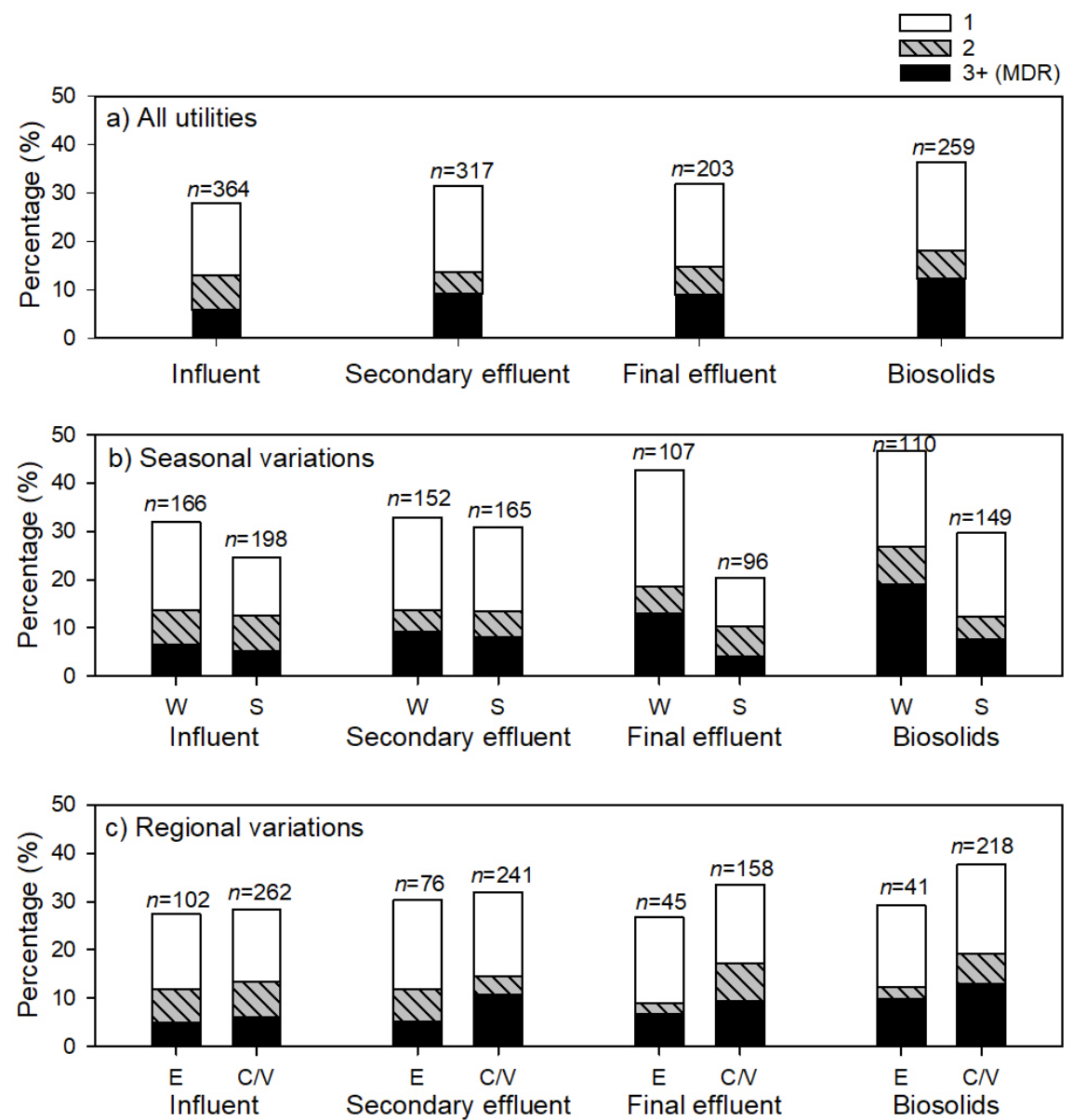

Figure 4. Percentage of $E$. coli isolates resistant to 1, 2, and 3 or more (multi-drug resistance; MDR) classes of antibiotics. E. coli isolated were collected from influent, secondary effluent, final effluent, and biosolids for a) all utilities $(n=17)$, b) samples collected in winter $(\mathrm{W})$ and summer (S), and c) samples collected from wastewater treatment utilities in Eastern Oregon (E) and coastal/valley $(\mathrm{C} / \mathrm{V})$ regions of Oregon. The total number of samples are shown above each bar.

\subsection{Co-occurrence of antibiotic-resistant $E$. coli phenotypes}

While most $(68.4 \%)$ of the $1143 \mathrm{E}$. coli isolates in our study were susceptible to all eight tested antibiotics, $31.6 \%$ of the $E$. coli isolates $(n=361)$ exhibited resistance to at least one antibiotic. Of these, $27.7 \%(n=100)$ carried MDR phenotypes. In influent, $28.0 \%(n=102)$ of E. coli isolates were resistant to at least one antibiotic and 5.8\% $(n=21)$ showed MDR phenotypes (Figure 4a). In secondary effluent, $31.6 \%(n=100)$ of isolated $E$. coli harbored resistance against tested antibiotics and 9.2\% $(n=29)$ were MDR (Figure 4a). In final effluent and biosolids, $32.0 \%(n=65)$ and $36.3 \%(n=94)$ of $E$. coli isolates were categorized as AMR and $8.9 \%(n=18)$ and $12.4 \%(n=32)$ were MDR, respectively (Figure 4a). Among the 100 
MDR E. coli isolates, $59.0 \%$ were resistant to three antibiotics, whereas $27.0 \%, 8.0 \%$, and $6.0 \%$ of the MDR isolates harbored resistances to four, five, and six antibiotics, respectively. Resistance to ampicillin was the most common phenotype among MDR isolates (observed in $91 \%$ of MDR isolates); followed by resistances to tetracycline $(82.0 \%)$, streptomycin $(72.0 \%)$, and SXT (64.0\%). The most common MDR phenotype combination included simultaneous resistances to ampicillin, streptomycin, and tetracycline $(n=49)$, followed by ampicillin, streptomycin, and SXT $(n=46)$.

Co-occurrences of resistance to tested antibiotics were assessed between the $E$. coli colonies that harbored at least two AMR phenotypes $(n=169)$. Resistance to cefotaxime, ceftazidime, and imipenem were observed in only 20,15, and 1 E. coli isolates, respectively, and were excluded from the analysis of AMR phenotypes' co-occurrences because of low statistical power. The occurrence of SXT-resistant E. coli showed significant positive correlations with ampicillin, streptomycin, and tetracycline ( $p<0.001$ with Bonferroni correction; Table 2). Moreover, of the $73 \mathrm{E}$. coli isolates with resistance to SXT, 87.7\% $(n=64)$ harbored MDR phenotype. Prevalence of SXT-resistance in $E$. coli has been previously associated with occurrence of class 1 integron genes, indicator of horizontal gene transfer (Shin et al., 2015). Moreover, co-occurrences of resistance were significant between ampicillin and ciprofloxacin and with streptomycin ( $p=0.03$ for all three correlations; $p>0.05$ with Bonferroni correction; Table 2).

Table 2. Co-occurrences of different phenotypes of antibiotic resistance in wastewater treatment utilities. Chi-square statistic values (p-values) are reported for chi-square tests for all isolates collected from different wastewater flows (i.e., influent, secondary, effluent, and biosolids). SXT: sulfamethoxazole/trimethoprim. $* p<0.05$, ** $p<0.01, * * * p<0.001$. Significant correlations with Bonferroni correction are highlighted in bold.

\begin{tabular}{lllll}
\hline $\begin{array}{l}\text { Resistance } \\
\text { phenotypes }\end{array}$ & Ampicillin & Ciprofloxacin & Streptomycin & SXT \\
\hline
\end{tabular}

Ampicillin

Ciprofloxacin $1.07(0.03 *)$

Streptomycin $4.98(0.03 *) \quad 4.75(0.03 *)$

$\begin{array}{llll}\text { SXT } & 19.44 & 2.17(0.14) & 23.10 \\ & (<\mathbf{0 . 0 0 1} * * *) & & (<\mathbf{0 . 0 0 1 * * * )}\end{array}$

$\begin{array}{lllll}\text { Tetracycline } & 0(1.0) & 0.67(0.41) & 0.62(0.43) & 32.4\end{array}$

$(<0.001 * * *)$

\subsection{ESBL-producing $E$. coli in wastewater treatment utilities across Oregon}

Our study is the first to report on ESBL-producing E. coli isolates in Oregon wastewater systems and the first to report this data for biosolids from the U.S. Of the $1143 \mathrm{E}$. coli colonies isolated from 246 samples, $1.2 \%$ tested positive for ESBL-producing enzyme $(n=13)$. These isolates were collected from nine different wastewater treatment utilities. The distribution of ESBL-producing isolates was fairly even between influent $(n=3)$, secondary effluent $(n=2)$, final effluent $(n=4)$, and biosolids $(n=4)$. Among the ESBL-producing E. coli, six were detected in winter and seven in summer. Of these 13 isolates, 11 were collected from the Oregon 
coast and the Willamette Valley, of which eight belonged to wastewater utilities with higher serving population densities. Moreover, 12 of the 13 ESBL-producing E. coli isolates harbored MDR phenotypes, of which seven showed resistance to six or more antibiotics. Among these ESBL-producing isolates, cefotaxime resistance was the most common AMR phenotype $(n=13)$ followed by ampicillin $(n=11)$, tetracycline $(n=11)$, ceftazidime $(n=10)$, ciprofloxacin $(n=9)$, SXT $(n=9)$, and streptomycin $(n=8)$. All ESBL-producing E. coli isolates were susceptible to imipenem. The only other study in the U.S., to our knowledge, on ESBL-producing E. coli in wastewater systems (primary clarifier and final effluent) reported $20 \%$ prevalence of carbapenemase, ESBL-associated genes, or both in antibiotic-resistant $E$. coli isolates collected in the states of New Jersey, Maryland, Ohio, Texas, Colorado, California (Hoelle et al., 2019). It is also important to note that we detected only one imipenem-resistant $E$. coli isolate, collected from a secondary effluent in winter. Carbapenems, such as imipenem, are the common treatment option for infections with ESBL-producing bacteria. Hence, the occurrence of imipenemresistant bacteria in the environment suggests clinical resistance to last resort antibiotics. ESBLproducing bacterial infections have been previously correlated with hospital stays of over six times longer than infections with non-ESBL-producing bacteria (Lautenbach et al., 2001). Longer hospital stays and delayed diagnoses invite more opportunity for lasting damage from these infections.

\section{Conclusion}

This study sheds light on the abundance and diversity of antibiotic-resistant E. coli in 17 wastewater treatment utilities across Oregon over winter and summer seasons. Amongst the 1143 collected $E$. coli isolates from 246 samples, AMR phenotypes were detected in $31.6 \%$ of the $E$. coli isolates from different flows and seasons throughout the study, with some isolates showing resistance to up to six classes of antibiotics. MDR phenotypes were observed among $27.7 \%$ of isolates with AMR phenotypes, and the most common combinations included simultaneous resistances to ampicillin, streptomycin, and tetracycline $(n=49)$, followed by ampicillin, streptomycin, and SXT $(n=46)$. Among tested phenotypes, ampicillin resistance was the most common AMR phenotype, followed by streptomycin and tetracycline. Significant correlations were observed between resistance to SXT and resistances to ampicillin, ciprofloxacin, and tetracycline $(p<0.001)$. Among collected $E$. coli isolates, 13 ESBL-positive and one imipenem resistance were detected. When analyzing the resistance phenotypes between different flows (i.e., influent, secondary effluent, final effluent, and biosolids), ciprofloxacin resistance was significantly more prevalent in biosolids compared to influent $(p<0.05)$ and tetracycline resistance was significantly lower in effluent as compared to influent $(p<0.05)$. Seasonal impact on AMR E. coli in wastewater influent was observed through significantly higher MAR index, ampicillin resistance prevalence, and ciprofloxacin resistance prevalence in summer compared to winter $(p<0.05)$. This state-wide study confirms the widespread proliferation of antibioticresistant, MDR, and ESBL-producing E. coli and further identifies wastewater surveillance as an epidemiological screening and identification tool.

\section{Declaration of Competing Interest}

The authors declare that they have no known competing financial interests or personal relationships that could have appeared to influence the work reported in this paper. 


\section{Acknowledgement}

This work was supported by the USDA National Institute of Food and Agriculture, Agricultural and Food Research Initiative Competitive Program, Agriculture Economics and Rural Communities, Grant No. 2018-67017-27631.

\section{References}

APHA, AWWA, WEF, 2012. Standard Methods for Examination of Water and Wastewater. 22nd ed., American Public Health Association, Washington, DC, USA.

Berendonk, T.U., Manaia, C.M., Merlin, C., Fatta-Kassinos, D., Cytryn, E., Walsh, F., Bürgmann, H., Sørum, H., Norström, M., Pons, M.-N., 2015. Tackling antibiotic resistance: the environmental framework. Nature Reviews Microbiology 13, 310-317.

Burch, T.R., Sadowsky, M.J., LaPara, T.M., 2013a. Aerobic digestion reduces the quantity of antibiotic resistance genes in residual municipal wastewater solids. Frontiers in microbiology 4, 17.

Burch, T.R., Sadowsky, M.J., LaPara, T.M., 2013b. Air-drying beds reduce the quantities of antibiotic resistance genes and class 1 integrons in residual municipal wastewater solids. Environmental science \& technology 47, 9965-9971.

CDC, 2019. Antibiotic Resistance Threats in the United States. Center for Disease Control and Prevention, U.S. Department of Health and Human Services.

CDC, 2013. Antibiotic Resistace Threats in the United States. Center for Disease Control and Prevention, U.S. Department of Health and Human Services.

CLSI, 2020. M100 Performance Standards for Antimicrobial Susceptibility Testing A CLSI supplement for global application. 30th Edition.

Durkin, M.J., Jafarzadeh, S.R., Hsueh, K., Sallah, Y.H., Munshi, K.D., Henderson, R.R., Fraser, V.J., 2018. Outpatient antibiotic prescription trends in the United States: a national cohort study. infection control \& hospital epidemiology 39, 584-589.

Golovko, O., Kumar, V., Fedorova, G., Randak, T., Grabic, R., 2014. Seasonal changes in antibiotics, antidepressants/psychiatric drugs, antihistamines and lipid regulators in a wastewater treatment plant. Chemosphere 111, 418-426.

Harnisz, M., Gołaś, I., Pietruk, M., 2011. Tetracycline-resistant bacteria as indicators of antimicrobial resistance in protected waters-The example of the Drwęca River Nature Reserve (Poland). Ecological indicators 11, 663-668.

Henriot, C.P., Martak, D., Cuenot, Q., Loup, C., Masclaux, H., Gillet, F., Bertrand, X., Hocquet, D., Bornette, G., 2019. Occurrence and ecological determinants of the contamination of floodplain wetlands with Klebsiella pneumoniae and pathogenic or antibiotic-resistant Escherichia coli. FEMS microbiology ecology 95, fiz097.

Hoelle, J., Johnson, J.R., Johnston, B.D., Kinkle, B., Boczek, L., Ryu, H., Hayes, S., 2019. Survey of US wastewater for carbapenem-resistant Enterobacteriaceae. Journal of water and health 17, 219-226.

Honda, R., Tachi, C., Yasuda, K., Hirata, T., Noguchi, M., Hara-Yamamura, H., YamamotoIkemoto, R., Watanabe, T., 2020. Estimated discharge of antibiotic-resistant bacteria from combined sewer overflows of urban sewage system. NPJ Clean Water 3, 1-7.

Korzeniewska, E., Harnisz, M., 2018. Relationship between modification of activated sludge wastewater treatment and changes in antibiotic resistance of bacteria. Science of the Total Environment 639, 304-315. 
Krumperman, P.H., 1983. Multiple antibiotic resistance indexing of Escherichia coli to identify high-risk sources of fecal contamination of foods. Appl Environ Microbiol 46, 165-170. https://doi.org/10.1128/AEM.46.1.165-170.1983

Kumar, M., Ram, B., Sewwandi, H., Honda, R., Chaminda, T., 2020. Treatment enhances the prevalence of antibiotic-resistant bacteria and antibiotic resistance genes in the wastewater of Sri Lanka, and India. Environmental research 183, 109179.

Lautenbach, E., Patel, J.B., Bilker, W.B., Edelstein, P.H., Fishman, N.O., 2001. ExtendedSpectrum $\beta$-Lactamase-Producing Escherichia coli and Klebsiella pneumoniae: Risk Factors for Infection and Impact of Resistance on Outcomes. Clinical Infectious Diseases 32, 1162-1171. https://doi.org/10.1086/319757

Lima-Bittencourt, C.I., Cursino, L., Gonçalves-Dornelas, H., Pontes, D.S., Nardi, R.M.D., Callisto, M., Chartone-Souza, E., Nascimento, A.M.A., 2007. Multiple antimicrobial resistance in Enterobacteriaceae isolates from pristine freshwater. Genet Mol Res 6, 510 521.

Logan, L.K., Zhang, L., Green, S.J., Dorevitch, S., Arango-Argoty, G.A., Reme, K., Garner, E., Aldstadt, J., Johnson-Walker, Y.J., Hayden, M.K., 2020. A Pilot Study of Chicago Waterways as Reservoirs of Multidrug-Resistant Enterobacteriaceae (MDR-Ent) in a High-Risk Region for Community-Acquired MDR-Ent Infection in Children. Antimicrobial Agents and Chemotherapy 64.

Manaia, C.M., Rocha, J., Scaccia, N., Marano, R., Radu, E., Biancullo, F., Cerqueira, F., Fortunato, G., Iakovides, I.C., Zammit, I., 2018. Antibiotic resistance in wastewater treatment plants: Tackling the black box. Environment international 115, 312-324.

Mays, C., Garza, G.L., Waite-Cusic, J., Radniecki, T.S., Navab-Daneshmand, T., 2021. Impact of biosolids amendment and wastewater effluent irrigation on enteric antibiotic-resistant bacteria - a greenhouse study. Water Research X 13, 100119. https://doi.org/10.1016/j.wroa.2021.100119

Mezrioui, N., Baleux, B., 1994. Resistance patterns of E. coli strains isolated from domestic sewage before and after treatment in both aerobic lagoon and activated sludge. Water Research 28, 2399-2406.

Miller, J.H., Novak, J.T., Knocke, W.R., Pruden, A., 2014. Elevation of antibiotic resistance genes at cold temperatures: implications for winter storage of sludge and biosolids. Letters in applied microbiology 59, 587-593.

Munir, M., Wong, K., Xagoraraki, I., 2011. Release of antibiotic resistant bacteria and genes in the effluent and biosolids of five wastewater utilities in Michigan. Water research 45, 681-693.

Quintela-Baluja, M., Abouelnaga, M., Romalde, J., Su, J.-Q., Yu, Y., Gomez-Lopez, M., Smets, B., Zhu, Y.-G., Graham, D.W., 2019. Spatial ecology of a wastewater network defines the antibiotic resistance genes in downstream receiving waters. Water research 162, 347357.

Ramsey, E.G., Royer, J., Bookstaver, P.B., Justo, J.A., Kohn, J., Albrecht, H., Al-Hasan, M.N., 2019. Seasonal variation in antimicrobial resistance rates of community-acquired Escherichia coli bloodstream isolates. International journal of antimicrobial agents 54, 17.

Sanchez, G. V, Master, R.N., Karlowsky, J.A., Bordon, J.M., 2012. In vitro antimicrobial resistance of urinary Escherichia coli isolates among US outpatients from 2000 to 2010. Antimicrobial agents and chemotherapy 56, 2181-2183. 
Shin, H.W., Lim, J., Kim, S., Kim, J., Kwon, G.C., Koo, S.H., 2015. Characterization of trimethoprim-sulfamethoxazole resistance genes and their relatedness to class 1 integron and insertion sequence common region in gram-negative bacilli. J Microbiol Biotechnol $25,137-142$.

Soucy, J.-P.R., Schmidt, A.M., Quach, C., Buckeridge, D.L., 2020. Fluoroquinolone Use and Seasonal Patterns of Ciprofloxacin Resistance in Community-Acquired Urinary Escherichia coli Infection in a Large Urban Center. American journal of epidemiology 189, 215-223.

Sousa, J.M., Macedo, G., Pedrosa, M., Becerra-Castro, C., Castro-Silva, S., Pereira, M.F.R., Silva, A.M.T., Nunes, O.C., Manaia, C.M., 2017. Ozonation and UV254 nm radiation for the removal of microorganisms and antibiotic resistance genes from urban wastewater. Journal of Hazardous Materials 323, 434-441.

Sui, Q., Zhang, J., Tong, J., Chen, M., Wei, Y., 2017. Seasonal variation and removal efficiency of antibiotic resistance genes during wastewater treatment of swine farms. Environmental Science and Pollution Research 24, 9048-9057.

Turolla, A., Cattaneo, M., Marazzi, F., Mezzanotte, V., Antonelli, M., 2018. Antibiotic resistant bacteria in urban sewage: role of full-scale wastewater treatment plants on environmental spreading. Chemosphere 191, 761-769.

US Climate Data, 2021. URL https://www.usclimatedata.com/

US EPA, 1999. Biossolids regulationsBiosolids Management Handbook.

US EPA, 1983. Methods for chemical analysis of water and wastes. Methods for chemical analysis of water and wastes 350-351.

WHO, 2017. Prioritization of pathogens to guide discovery, research and development of new antibiotics for drug resistant bacterial infections, including tuberculosis (No. WHO/EMP/IAU/2017.12). World Health Organization, Geneva, Switzerland.

Zhang, Y., Marrs, C.F., Simon, C., Xi, C., 2009. Wastewater treatment contributes to selective increase of antibiotic resistance among Acinetobacter spp. Science of the Total Environment 407, 3702-3706. 